\title{
Fatigue Subordinate Domain
}

National Cancer Institute

\section{Source}

National Cancer Institute. Fatigue Subordinate Domain. NCI Thesaurus. Code C122347.

The collection of PROMIS item scales that assess fatigue that is likely to decrease an individual's ability to carry out daily activities, including the ability to work effectively and to function at their usual level in family or social roles. 